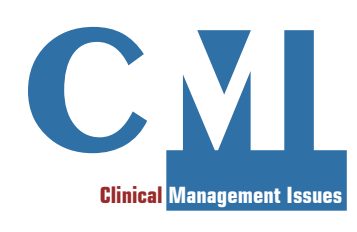

\title{
Use of natural and homeopathic remedies in children ailments
}

\begin{abstract}
In recent decades the use of CAM (Complementary and Alternative Medicine) has increased significantly, not only among adults but also in the pediatric population. Perceived efficacy of homeopathic or natural treatments, fear of drug adverse effects, dissatisfaction with conventional medicine, and the need for more personal attention are the main reasons given by parents who treat their children with homeopathy.

In the present paper the use of natural and homeopathic remedies for the treatment of children ailments are considered. In particular we focus on minor disorders of early childhood with a major impact on the well-being of the whole family, namely infant colic, teething, upper respiratory tract infections (URTIs) and tonsillopharyngitis. The results of recent studies on homeopathic products for the treatment of these disorders are presented and discussed.
\end{abstract}

Keywords: Homeopathy; Children; Infant colic; Teething; Upper respiratory tract infections (URTIs); Tonsillopharyngitis

CMI 2016; 10(2): 33-48

http://dx.doi.org/10.7175/cmi.v10i2.1252
${ }^{1}$ International Health Centre, The Hague,

Netherlands

2 Centro de Salud

La Cala,Servicio

Andaluz de Salud,

Mijas Costa, Spain

3 Deutsche Homöopathie-

Union, DHU-Arzneimittel

$\mathrm{GmbH} \& \mathrm{Co} . \mathrm{KG}$

Karlsruhe-Germany

\section{INTRODUCTION}

The National Institutes of Health (NIH) has defined complementary and alternative medicine (CAM) as "a group of diverse medical and health care systems, practices, and products that are not presently considered to be part of conventional medicine" $[1,2]$. The National Center for Complementary and Alternative Medicine (NCCAM) classifies CAM therapies into five categories: alternative medical systems (homeopathic and naturopathic, Chinese, and Ayurvedic medicine), mind-body interventions, biologically based therapies (herbs, foods, etc.), manipulative and body-based methods, energy therapies $[1,2]$.

In recent decades the use of CAM has increased significantly, not only among adults but also in the pediatric population.

Zuzak et al. recently conducted a pan-European review about CAM in pediatrics, realized by combining data published in inter- national journals, data from local or national surveys in original language conveyed by local experts, and expert perspectives about CAM availability, quality, use and popularity in their countries. According to this study, conducted in 20 European countries, $56 \%$ of the European population in general has used CAM at least once during the year preceding the survey. For the pediatric population the rate was similar (52\%), confirming the growing interest in CAM reported by pediatricians and institutions. Homeopathy and herbal medicine was identified as the most popular CAM therapies in Europe [3].

In the United States the percentage of healthy children seen in outpatient pediatric clinics that uses CAM is between $20-40 \%$ and rises to values above $50 \%$ in the case of children with chronic diseases, almost always in conjunction with mainstream care [4].

An interesting analysis on the extent of homeopathic prescriptions in children was conducted by Ekins-Daukes and colleagues
Corresponding author Silvia Salatino

Silvia.Salatino@dhu.de

Disclosure

Stephen Buskin and María Pilar Riveros Huckstadt are members of the DHU Advisory Board. Silvia Salatino is an employee of DHU. The writing of this article was supported by DHU 
in Scotland. Majority of these prescriptions were made for children under 1 year of age (8.0/1000 registered children) and the most common conditions for which homeopathic medicines were prescribed were colic (85\%), cuts and bruises $(52 \%)$, teething (49\%), dermatological conditions (32\%), earache (21\%), influenza and upper respiratory tract infections $(16 \%)$, cough $(16 \%)$, vomiting $(16 \%)$, irritability (15\%) and diarrhea (12\%) [5].

Recently an international survey was performed in order to provide insights into physician' attitude towards the use of homeopathy and natural remedies in pediatric practice. 582 general pediatricians and general practitioners treating pediatric conditions in 6 countries (Germany, Spain, Russia, Bulgaria, Colombia, Israel) were involved. Herbal medicine and homeopathic products amounted to $17 \%$ and $15 \%$ of total prescriptions in pediatrics, respectively. Upper respiratory tract infections (URTIs), infant colic, sleep disturbances and recurrent infections were the main causes for which natural remedies and homeopathic products were used. In the majority of cases they are used as complementary treatment together with conventional drugs. The study confirms high interest of physicians in natural remedies and homeopathy, however their knowledge level is heterogeneous. The concern about side effects and the use for themselves are the main factor that drives parents to the use of homeopathy and natural remedies [6].

Perceived efficacy of homeopathic or natural treatments, fear of drug adverse effects, dissatisfaction with conventional medicine, and the need for more personal attention are the main reasons given by parents who treat their children with homeopathy [4].

Recognizing the increasing use of CAM in children, many institutions, like the American Academy of Pediatrics (AAP), have decided to provide information and support for health professionals. In the 2001 AAP Periodic Survey of Fellows, 73\% of pediatricians agreed that it is the role of pediatricians to provide patients/families with information about all potential treatment options for the patient's condition, and $54 \%$ agreed that pediatricians should consider the use of all potential therapies, not just those of mainstream medicine, when treating patients [7].

Efforts to include education and training for CAM therapies in medical school programs have also become popular in some European countries $[8,9]$.
Despite the long tradition of homeopathy, and its spread around the world, the debate on this issue is always very heated. In recent years a number of studies have been published on the effectiveness of homeopathy in children. For example, several studies conducted in different countries on the management of acute respiratory infections and acute otitis media showed a significant rapid improvement upon homeopathic medications compared to conventional treatment and less use of antibiotics [10-12].

Some researchers have highlighted an interesting peculiarity: publication bias in CAM research is «opposite that of conventional medicine; that is, negative studies are more likely to be published in well-known journals, and positive studies are more likely to be published in non-English language and often complimentary medicine journals» [13].The most controversial aspect of homeopathy is the ultra-dilutions and the lack of solid data on the mechanism of action. Theories on the possible explanation of mechanism of action of homeopathy within the context of nanomedicine have been recently published, although still hotly debated [14]. A recent publication by Rutten et al. explores the current evidence for homeopathy reporting three meta-analyses by Kleijnen, Linde and Cucherat published from 1991-2000 that reached positive conclusions and a review by Shang in 2005 that reached negative conclusions [15-19].

In the present paper the use of natural and homeopathic remedies for the treatment of children ailments are considered. In particular we focus on minor disorders of early childhood with a major impact on the well-being of the whole family namely infant colic, teething, upper respiratory tract infections (URTIs) and tonsillopharyngitis. The results of recent studies on homeopathic products for the treatment of these disorders are presented and discussed [20-24].

\section{INFANT COLIC}

\section{Definition}

A common definition of infantile colic comes from Morris A. Wessel and colleagues, the so-called "rule of 3": a condition of a healthy, well-fed baby in which it shows periods of intense, unexplained crying lasting more than at least 3 hours a day, on at least 3 days (per week), of at least 3 weeks [25]. 
The prevalence of infantile colic given in the scientific literature widely varies and ranges from $5-40 \%$, depending on the study methodology, the population and the definition of infantile colic used [26].

Although benign and self-limiting, it is associated with higher levels of maternal stress and anxiety: the impact of prolonged and inconsolable crying in children with infantile colic causing sleepless nights, stress, frustration and exhaustion, especially in first-time parents [27-29].

Despite being a very common disorder, the causes are not yet completely clarified. Etiopathology of this condition includes both gastrointestinal and non-gastrointestinal factors, such as hypersensitivity to baby formula, alteration in gut microflora, excessive gas in the intestine, intestinal hypo- / hypermotility, immature digestive system, over-stimulation and (hyper-)sensitivity to the environment, reflection of problems in parent-infant interaction, maternal smoking.

\section{Treatment}

The above possible causes of infantile colic have led to a variety of available treatments, ranging from pharmaceutical therapies, dietary interventions, behavioral strategies, and physical remedies. At first, the most commonly recommended approach is to discuss the usually natural and self-limiting character of infantile colic with parents and to offer some methods to parents for calming the baby.

Pharmaceutical therapies includes simethicone, dicyclomine hydrochloride and cimetropium bromide, but results from literature on simethicone and dicyclomine for infantile colic do not suggest these to be fully effective or appropriate treatment options [30-33]. A trial by Savino et al. found cimetropium bromide more effective than placebo in reducing the duration of crying in children with infantile colic but there were reported side effects in terms of increased sleepiness $[34,35]$. Safety is a critical issues in infants, and a major concern for parents: in literature there have been reports of infants who experienced serious adverse events, such as serious respiratory symptoms seizures, syncope, pulse rate fluctuations and muscular hypotonia after taking dicyclomine hydrochloride syrup; no causal relationship has been established but dicyclomine hydrochloride is now contraindicated in infants $<6$ months and in nursing mothers $[35,36]$. Recent research is now targeting the promising role

\begin{tabular}{|c|c|}
\hline Active ingredient & Therapeutic action / characteristics \\
\hline Chamomilla D6 & $\begin{array}{l}\text { - Infant colic with flatulence (infant gaseous colic) } \\
\text { - Hypersensitivity to pain } \\
\text { - Restlessness together with dissatisfaction }\end{array}$ \\
\hline Cina D6 & $\begin{array}{l}\text { - Spasms of the gastrointestinal tract } \\
\text { - Aversion to breast-milk (ingestion causes colic and } \\
\text { diarrhoea; the baby frequently spits up sour milkJ } \\
\text { - Marked irritability, physical and mental }\end{array}$ \\
\hline Colocynthis D6 & $\begin{array}{l}\text { - Colic / colicky pain better by pressure and heat (warm } \\
\text { applications) } \\
\text { - Griping pain around the navel }\end{array}$ \\
\hline Lac defloratum D6 & $\begin{array}{l}\text { - Digestive disorders due to intolerance of milk } \\
\text { - General aggravation of symptoms from drinking milk }\end{array}$ \\
\hline $\begin{array}{l}\text { Magnesium } \\
\text { chloratum D6 }\end{array}$ & $\begin{array}{l}\text { - Constipation with dry, pellet-like stool } \\
\text { - Problems to digest milk (especially during difficult } \\
\text { dentition) }\end{array}$ \\
\hline
\end{tabular}

of Lactobacillus reuteri in the treatment of infantile colic $[37,38]$.

Nutritional interventions are closely related to the type of feeding received by the child. In case of breast-fed infants, a monitored low allergen maternal diet avoiding cow's milk and dairy food with appropriate intake of vitamins and minerals may be suggested, while the first-line for bottle-fed infants is represented by formulas based on partially hydrolyzed whey proteins with prebiotic oligosaccharides [39].

A considerable number of behavioral strategies and physical remedies resulting from tradition and practical experience are suggested, such as offering an atmosphere of security to the baby, decreasing stimulation, offering "white noise", massaging or rocking the baby. Despite the lack of evidence published in the literature, this type of remedies may be useful for some children [39].

In the absence of standard of care for treatment of infant colic, CAM has assumed an increasingly important role in the management of infantile colic. In particular, it is recognized the use of herbal supplements (i.e. containing chamomile, fennel, vervain, licorice, balm-mint) $[40,41]$ and homeopathic products [42].

\section{Colikind ${ }^{\circledR}$ (use and dosage)}

Colikind $^{\circledR}$ (Deutsche Homöopathie Union, DHU, Karlsruhe, Germany) is natural combined medication that is indicated for the treatment of infantile colic and flatulence. It is composed of a combination of 5 single remedies: Chamomilla D6, Cina D6, Colocynthis D6, Lac defloratum D6
Table I. Colikind ${ }^{\circledR}$ active ingredients and therapeutic action 
Table II. Treatment options [20]

Table III. Subjective complaints and objective symptoms assessed in the study [20]

\section{Bhildren 0-6 years}

Acute symptoms: 3 drops / hour (max. 6 times a day) Afterwards: 3 drops 3 times a day
1 measuring spoon of the emulsion taken 3-5 times a day during meals (from a baby bottle or mixed with food and drink

\begin{tabular}{|l|l|}
\hline \multicolumn{1}{|l|}{ Subjective complaints } & $\begin{array}{l}\text { - Unexplained restlessness } \\
\text { - Sleep and appetite disturbances } \\
\text { - Increased crying while feeding } \\
\text { - Regurgitation } \\
\text { - Vomiting } \\
\text { - Stool softening } \\
\text { - Constipation and flatulence } \\
\text { - Abdominal bloating }\end{array}$ \\
$\begin{array}{ll}\text { Table III. Subjective } \\
\text { complaints and objective } \\
\text { symptoms assessed in the } \\
\text { study [20] }\end{array}$ & $\begin{array}{l}\text { - Intestinal rumbling } \\
\text { - Tenderness and intestinal spasm on palpation } \\
\text { - Changes in stool }\end{array}$ \\
& - Dryness of the skin and mucosa \\
& - Skin pallor \\
& - Coating and geographism of the tongue
\end{tabular}

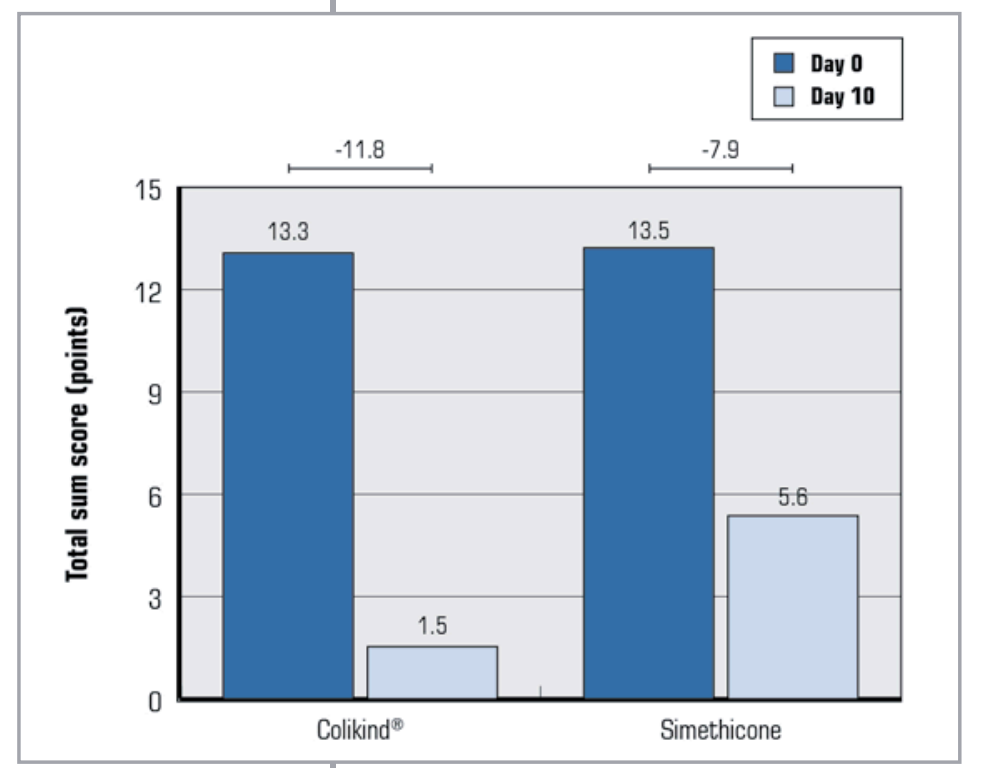

Figure 1. Decrease in total sum score (subjective + objective symptoms). Adapted from [20]
In case of acute condition, Colikind ${ }^{\circledR}$ can be administered at a dose of 3 drops up to a max. of 6 times a day; after improvement, treatment can be continued with 3 drops 3 times a day [43].

\section{From literature}

In 2010 an open, prospective, multicenter, comparative study on Colikind ${ }^{\circledR}$ was published by Ilyenko and colleagues [20]. Aim of the study was the evaluation of the effectiveness, safety and tolerability of Colikind ${ }^{\circledR}$ compared to Simethicone in children with infantile colic and/or meteorism. The study population was 200 pediatric patients aged 2 months to 6 years of both sexes. Table II summarized the treatment options.

Comparative evaluation of the efficacies of the study agents was performed in terms of changes in the severity of subjective complaints and objective symptoms at 3,7, and 10 day after the start of treatment. In Table III subjective complaints and objective symptoms are reported. Clinical symptoms were assessed by the physician at each visit, while overall outcome of treatment, treatment satisfaction, safety and tolerability of study medication were assessed both by physicians and parents.

On day 10 , both treatment groups showed a significant improvement of their subjective and objective symptoms, whereas Colikind ${ }^{\circledR}$ showed to be significantly more effective $(p<0.0001)$. Consequently, the decrease 

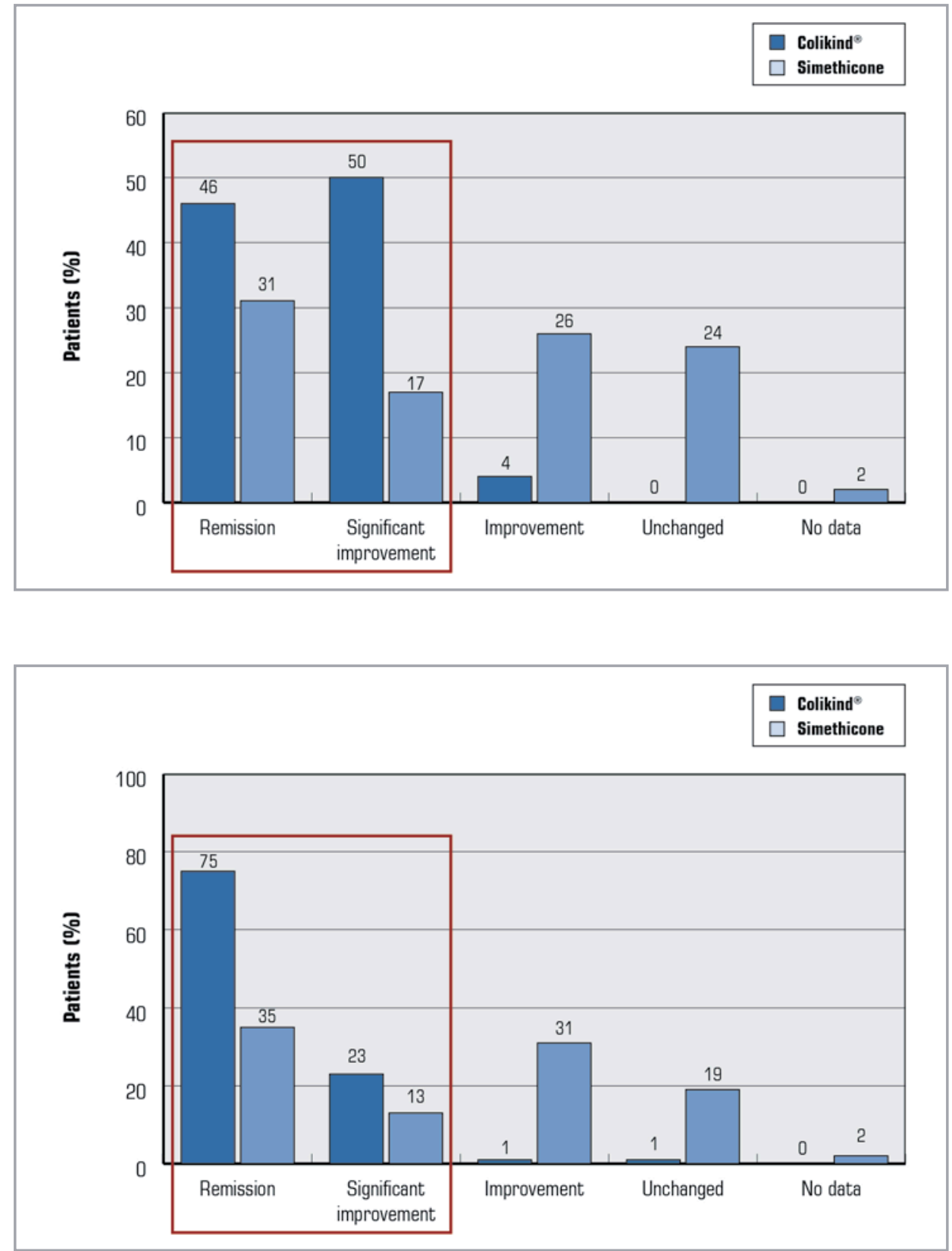

Figure 2. Overall outcome of treatment on day 10, assessed by physicians. Adapted from [20]

Figure 3. Overall outcome of treatment on day 10, assessed by parents. Adapted from [20]

in total sum score (subjective complaints + objective symptoms) was more pronounced in the group of children treated with $\mathrm{Co}^{-}$ likind $^{\circledR}$ (Figure 1).

After 10 days of treatment, $96 \%$ of patients treated with Colikind ${ }^{\circledR}$ showed a "remission" or a "significant improvement" of symptoms according to the physicians' assessment (Figure 2).

Parents' assessment of overall outcome after 10 days of treatment with Colikind ${ }^{\circledR}$ was even better.

In total, $98 \%$ benefitted from the treatment with Colikind $^{\circledR}$ - there of $75 \%$ of patients showed a "remission" of symptoms (Figure 3).
Significantly more parents were "very satisfied / satisfied" with treatment in the $\mathrm{Co}^{-}$ likind ${ }^{\circledR}$ group compared to the Simethicone group ( $\mathrm{p}<0.001)$. In addition, none of the parents in the Colikind ${ }^{\circledR}$ group was "dissatisfied" with treatment, whereas this applied to $22 \%$ of parents in the Simethicone group. Tolerability of Colikind ${ }^{\circledR}$ was rated "very good" or "good" in all patients, whereas in the Simethicone group, there were $6 \%$ of parents and $7 \%$ of physicians who rated tolerability only as "satisfied". In the study group treated with Colikind ${ }^{\circledR} 1$ adverse event (AE) but no drug-related AE (i.e. adverse drug reaction (ADR)) was reported. In the control group 5 children $(5 / 100,5 \%)$ treated with 
Simethicone were observed to suffer from an $\mathrm{AE}$, whereas 1 event was assessed as being related to the intake of Simethicone (ADR).

According to the results of this study, both medications (Colikind ${ }^{\circledR}$ and Simethicone) were effective and safe and can thus be recommended. However the Authors highlighted that in the Colikind ${ }^{\circledR}$ group more benefits were reported, such as quicker remission, faster decrease in the degree of the severity of subjective complaints and objective symptoms, the greater parents' satisfaction, the tolerability and the excellent safety profile of Colikind ${ }^{\circledR}$, emphasized by the lack of adverse drug reaction.

\section{TEETHING}

\section{Definition}

Teething is known as a natural process by which the first teeth appear in children. A variety of symptoms has been shown to accompany teething, including fever, pain, irritability, sleep problems, mouthing/biting, drooling, decreased oral intake, gum inflammation, runny nose, and diarrhea [44].

The onset of the primary incisors is usually around 6-12 months: in the same period the circulating maternal humoral immunity decreases, and the child's own humoral immunity develops [45]. The simultaneous presence of these events often makes this period difficult and distressing for both the child and their respective parents and accompanied by a number of relatively minor symptoms [45]. Teething symptoms in children can create much distress in parents [21].

\section{Treatment}

There are many remedies used by parents to relieve the symptoms of teething, often derived from tradition or experience of friends and family.

Pharmacological therapies include topical local anesthetics (i.e. lidocaine based preparations and topical benzocaine gel), topical choline salicylate-based products, and systemic analgesics. However, a standard of care is not established in the treatment of teething disturbances, use of some medications might be associated with unwanted side effects and for some topical teething gels cases of potential life-threatening risks have been reported $[21,46]$. In 2011 the US Food and Drug Administration (FDA) has released a document to recommend not to used benzocaine products on children $<2$ years without medical advice [47].

Non pharmacological remedies include teething rings, pacifier, hard food like bread, frozen fruits and vegetables. The relief derived from the low temperature of the objects, that cause local vasoconstriction, and by the pressure exerted on the gums through the biting on hard objects $[21,45]$. These remedies are widely used and have few contraindications. It is crucial, however, to be very careful to avoid the chocking risk. It is also recommended to use only sugar-free objects and not to add medicine to food or feeding bottles, as their dosage cannot be checked.

\section{Dentokind ${ }^{\circledR}$ (use and dosage)}

Dentokind $^{\circledR}$ (Deutsche HomöopathieUnion, DHU, Karlsruhe, Germany) is a complex homeopathic product containing five individual homeopathic substances: Belladonna D6, Chamomilla D6, Ferrum phosphoricum D6, Hepar sulfuris D12 and Pulsatilla D6 [48]. It is indicated for the treatment of teething symptoms such as irritability, restlessness, earache, painful gums, mild fever and softened stools in babies and children. It is available as tablets allowed to dissolve slowly in the mouth. For usage in small children, tablets can be dissolved in a little bit of water. For children $<1$ year the suggested dosage is 1 tablet every hour, up to a maximum of 6 tablets a day, in acute condition; the treatment can be extended after improvement at a dosage of 1 tablet, 3 times a day. For children 1-6 years the suggested dosage is 2 tablets every hour, up to a maximum of 12 tablets a day, in acute condition; the treatment can be extended after improvement at a dosage of 2 tablet, 3 times a day. An interval of at least half an hour to meals should be kept [48].

\section{From literature}

In 2015 a prospective, multicenter, randomized, open-label, comparative, controlled clinical trial on the clinical use of Dentokind ${ }^{\circledR}$ was published by Jong and colleagues [21]. The study, required for Dentokind ${ }^{\circledR}$ marketing authorization in Russian Federation, compared Dentokind ${ }^{\circledR}$ to another homeopathic product already authorized in the Federation. The study population consisted of 200 pediatric patients up to 6 years of age.

Dentokind ${ }^{\circledR}$ was administered orally for seven days. Children aged up to one year 
received Dentokind ${ }^{\circledR}$ tablets with a dosage regime of one tablet every hour up to six tablets per day (acute symptoms). After symptoms reduced one tablet three times a day was administered. Children aged 1-6 years received two tablets every hour up to a maximum of twelve tablets per day (acute symptoms). After symptoms reduction the dosage was two tablets three times per day. The other homeopathic medication was administered rectally for a period of seven days. For children aged up to six months the maximum daily dose was two suppositories a day. Children older than six months of age received a maximum of four suppositories (at a body temperature of $\geq 37.5^{\circ} \mathrm{C}$ ) a day. When body temperature normalized one suppository was used for further 3-4 days 1-2 times per day (with preventive purpose).

Primary endpoints were changes in total severity scores of subjective complaints (TSSC) and changes in total severity scores of clinical signs (TSCS) after treatment with study medication for 3-5-7 days. In Table IV subjective complaints and clinical signs are reported.

In the Dentokind group the assessment of TSCC recorded a reduction from 7.0 (baseline median value) to 3.0 (Day 3-5) and 1.0 at Day 7, while in the control group TSSC values decreased from 5.0 (baseline median value) to 3.0 (Day 3-5) and 1.0 at Day 7.

The study showed a reduction also in the TSCS values, which decreased from 6.0 (baseline median value) to 3.0 (Day 3-5) and 1.0 (Day 7) in the Dentokind group, and from 5.0 (baseline median value) to 4.0 (Day 3-5) and 1.0 (Day 7) in the control group.

\begin{tabular}{|l|l|}
\hline Subjective complaints & - Unmotivated anxiety \\
& - Gingival tenderness and appetite disorder \\
- Otalgy \\
Clinical signs & - Stool softening \\
& - Sleep-onset insomnia and frequent awakenings \\
& - Singiva hyperemia \\
- Gingiva swelling \\
- Hematoma and hyperemia around the mouth \\
- Drooling and hyperthermia
\end{tabular}

Improvement of individual complaints and individual signs after 7 days of treatment was observed in both treatment groups-except for the complaint sleep-onset insomnia. Compared to the other homeopathic medication improvement of the individual complaints gingival tenderness and appetite disorder and of the signs gingival hyperemia and gingival swelling was observed in significantly more children of the Dentokind ${ }^{\circledR}$ group (Armitage Trend Test: $\mathrm{p}<0.05$; FAS).

After 7 days of treatment children treated with Dentokind ${ }^{\circledR}$ had a 5-times higher odds of showing improvement in total severity score of subjective complaints than children treated with the other homeopathic medication and a 2.5-times higher odds of showing improvement in the total severity score of objective clinical signs.

After 7 days of treatment with Dentokind $^{\circledR}$ almost all parents and investigators ( $n=99$ out of 100 each) of the Dentokind ${ }^{\circledR}$ group rated "no complaints" or "major improvements" (Figure 4). Almost all parents ( $n=99$ out of 100$)$ of the Dentokind ${ }^{\circledR}$ group were very satisfied or satisfied with the
Table IV. Subjective complaints (TSSC) and clinical signs (TSCS) assessed in the study [21]

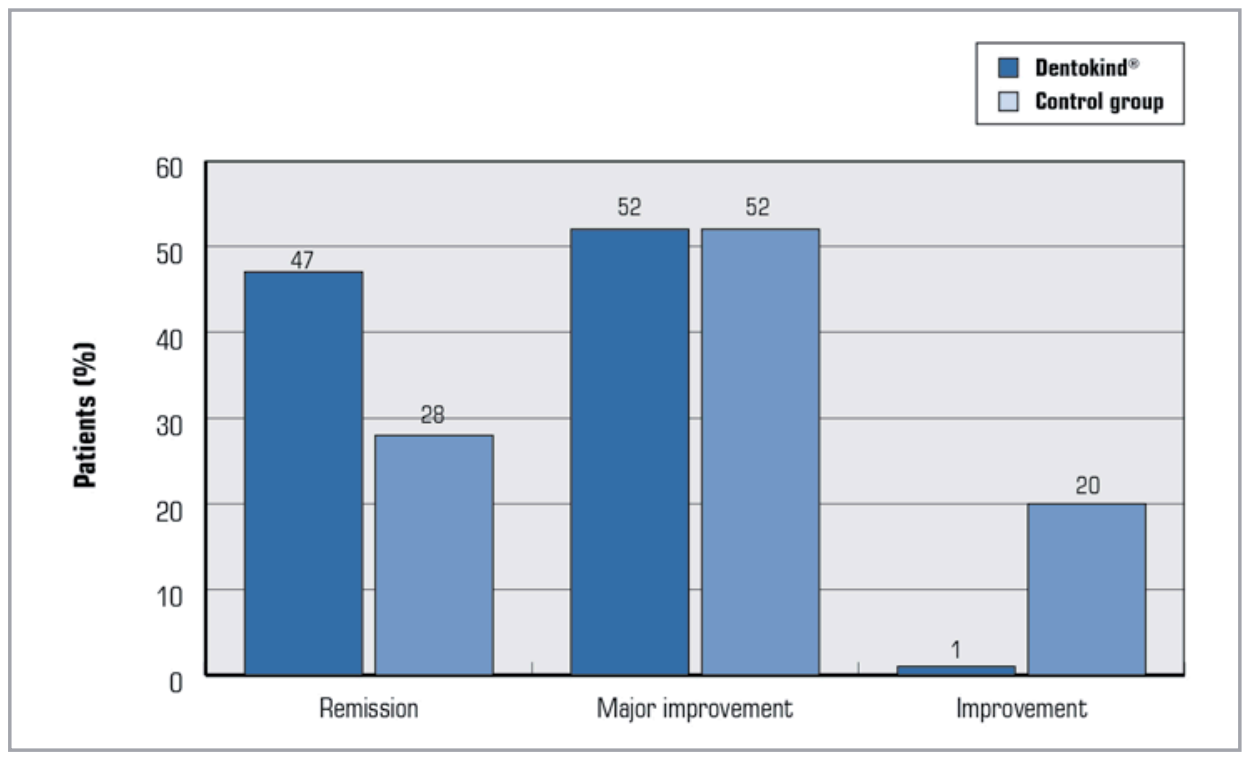

Figure 4. Overall outcome on day 7 , assessed by physicians. Adapted from [21] 
Figure 5. Treatment satisfaction on day 7 , assessed by parents. Adapted from [21]

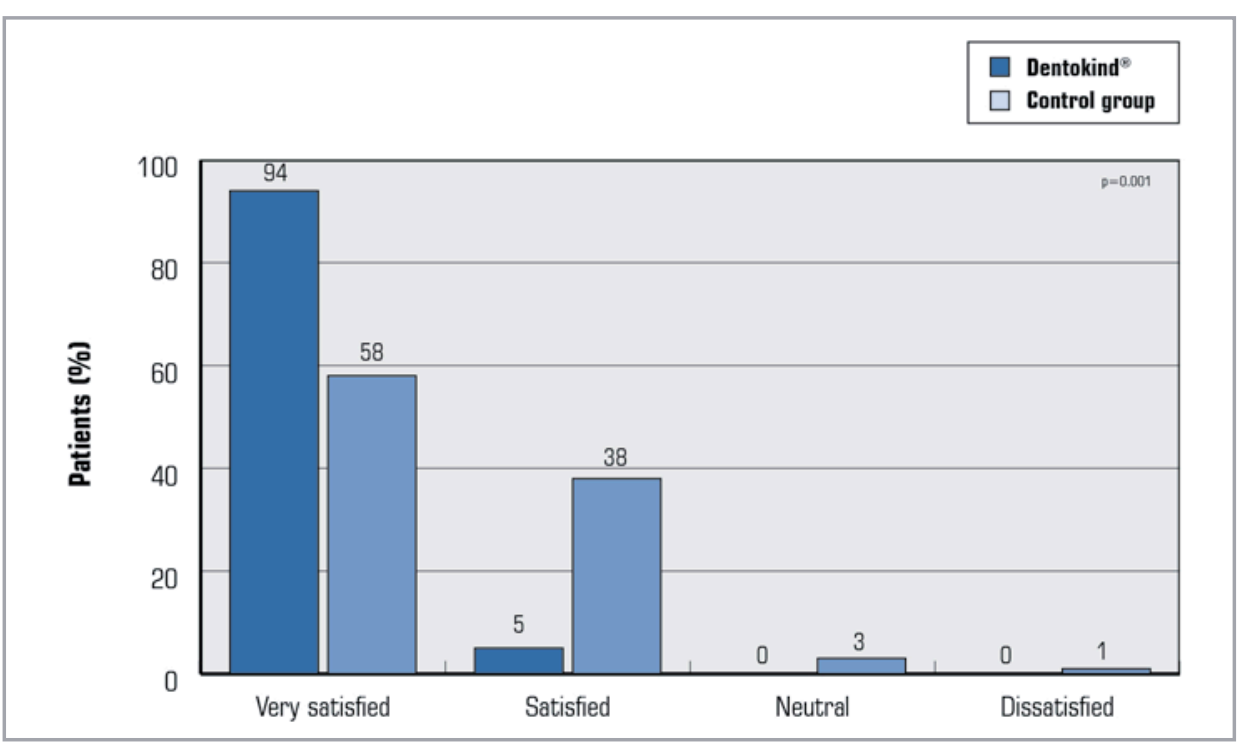

treatment. In comparison with the other product, the treatment satisfaction in Dentokind ${ }^{\circledR}$ group was significantly better $(\mathrm{Ar}-$ mitage Trend Test: $\mathrm{p}<0.0001 ; \mathrm{FAS}$ ) (Figure 5).

During the treatment period $1.5 \%$ children experienced AEs. The AEs occurred in 3 children of the control group. In Dentokind ${ }^{\circledR}$ group no AEs occurred. Almost all parents and investigators rated the tolerability of Dentokind ${ }^{\circledR}$ as "very good" or "good". Compared to the control group the outcome in the Dentokind ${ }^{\circledR}$ group was significantly better (Armitage Trend Test: $\mathrm{p}<0.0001$; FAS).

The study demonstrated that Dentokind ${ }^{\circledR}$ reduced total severity scores of subjective complaints, including individual symptoms such as unmotivated anxiety, gingival tenderness, appetite disorders and otalgy in teething children after 7 days of treatment. Total severity scores of clinical signs also lowered after 7 days of treatment in both groups. Dentokind ${ }^{{ }}$seems therefore a "pragmatic treatment alternative" to conventional OTC teething gels for symptoms relief of painful teething in children [21].

\section{UPPER RESPIRATORY TRACT INFECTIONS (URTIS)}

\section{Definition}

Upper respiratory tract infections (URTIs) or common colds represent the most frequently occurring illness in the world. Although they are usually self-limiting conditions, they are a leading cause of missed days from work and school, with a relevant economic burden [49].

Sore throat, runny nose, general malaise, fever, nasal congestion and cough are most common symptoms [22].

The specific immune status of children in the first years of life makes them especially vulnerable to viral infections [50]. In literature about 4-8 episodes of viral infection per year per child are recorded [50]. The majority of URTIs are caused by viral pathogens, most commonly rhinoviruses, but also influenza viruses [22].

URTIs are even the most frequent cause of antibiotic prescriptions in pediatric outpatient care. This represents a serious health problem globally since inappropriate use of antibiotics has a strong impact the increase of bacterial respiratory pathogens [51,52].

\section{Treatment}

Since there is no approved specific therapy for URTIs, treatment is mainly symptomatic. The most common pharmacological treatments are antipyretics, anti-inflammatory drugs, expectorants, decongestants, and cough suppressants [21]. A number of other remedies are available, such as vitamins, herbal supplements and homeopathic medicine. Data relating to the Germany showed that about $7 \%$ of all pediatric prescriptions for the respiratory tract system are not officially licensed for use in children [53].

As mentioned above, a key issue concerns the prescription of antibiotics, that are widely prescribed, but often inappropriate; overuse can lead to the development 
of community-acquired resistant pathogens which are an increasing and serious health burden [50]. The results of a nationwide US survey published in 2004 showed $38 \%$ of more than 6.5 million visits (primary practice, outpatient, and emergency department) by children and adults with a diagnosis of influenza were associated with antibiotic prescriptions. Studies limited to children demonstrated even higher rates of antibiotic treatment in children diagnosed with viral infections [54].

There are many factors that contribute to an inappropriate antibiotic prescription, including diagnostic uncertainty, lack of knowledge, socio-cultural and economic pressures, meeting parental expectations [51].

Natural remedies, and homeopathy in particular, can be used in the management of URTIs. An integrative approach to these infections may help reduce excessive antibiotic prescription [55].

\section{Influcid ${ }^{\circledR}$ (use and dosage)}

Influcid ${ }^{\circledR}$ (Deutsche HomöopathieUnion, DHU, Karlsruhe, Germany) is a homeopathic preparation containing a fixed combination of 6 homeopathic singles substances: Aconitum D3, Bryonia D2, Eupatorium perfoliatum D1, Gelsemium D3, Ipecacuanha D3 and Phosphorus D5 [56]. Launched in Germany in 1928, now it is marketed in 22 countries worldwide [22].

In acute conditions, and in children below 12 years, the suggested dose is 1 tablet every
2 hours, up to a maximum of 8 tablets per day, until improvement occurs; for subsequent treatment the dose is 1 tablet 3 times per day. The same dosage ( 1 tablet 3 times per day) is suggested for prevention of infections. Tablets should be dissolved slowly in the mouth: for small children, they can be dissolved in a little bit of water. An interval of at least half an hour to meals should be kept [56].

Efficacy and safety of Influcid ${ }^{\circledR}$ (IFC) in the treatment of flu-like infections and URTIs were demonstrated in several studies: in the multicenter open study conducted by Heger on a total of 600 patients (333 adults and 267 children) with URTIs, about $90 \%$ of patients reported an improvement after 3 days [57].

\section{From literature}

In 2015 a randomized, standard-treatment controlled, parallel group, open, multicenter and multinational clinical trial was published by Thinesse-Mallwitz and colleagues [22]. Aim of the study was to evaluate the effectiveness and safety of IFC as an add-on to symptomatic standard treatments of URTIs. A total of 523 patients presenting with clinical signs and symptoms of an URTI with a duration up to 24 $h$, accompanied by fever were randomized. The standard treatment (ST) group received paracetamol, ambroxol and/or oxymetazoline; the IFC group received the same symptomatic treatment plus IFC for 7 days. Patients evaluation was performed by in-

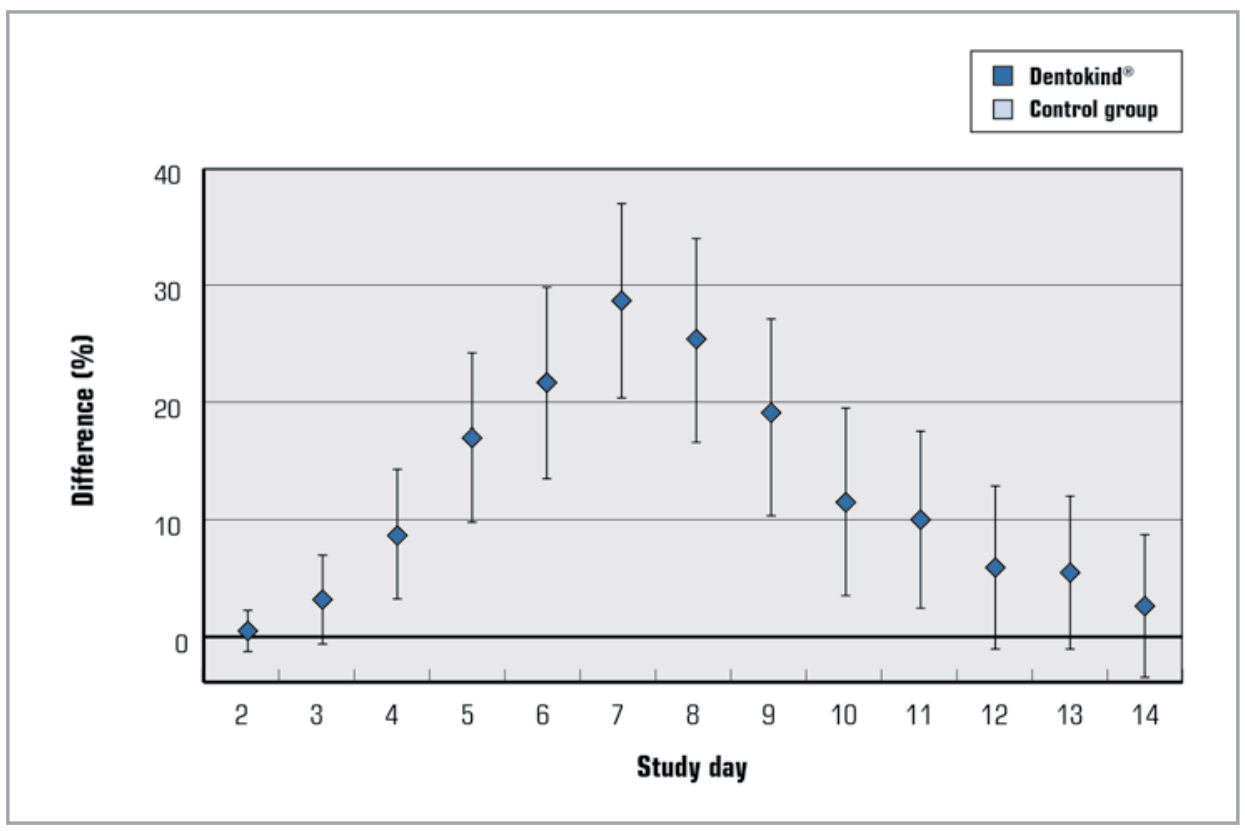

Figure 6. Betweengroup differences in the percentage of treatment responders (IFC minus ST) by study day (including 95\% CIs) Adapted from [22] 
Figure 7. Ability to perform normal daily activities. Adapted from [22]

Figure 8. Cumulated intake of standard symptomatic medication. Adapted from [22]
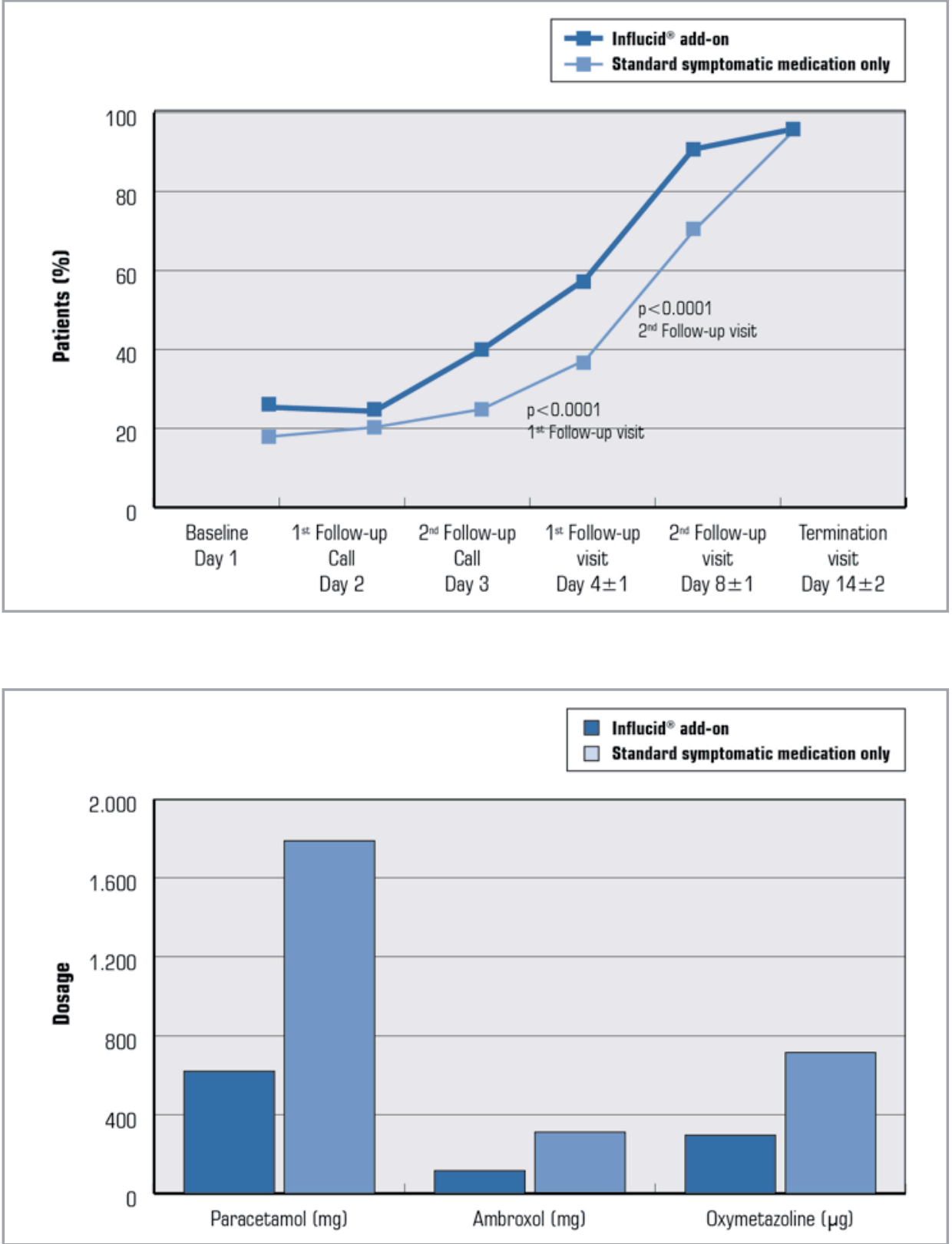

vestigators at baseline (day 1 ), and on day $4,8,15$. During the first 72 hours, patients $\geq 12$ years took 12 tablets a day (1 tablet every hour) while patients $<12$ years took 8 tablets per day (1 tablet every 2 hours); during the following 96 hours the IFC dosage was 2 tablets 3 times a day for patients $\geq 12$ years and 1 tablet 3 times a day for children.

The primary outcome was "treatment response" defined as a combination of mean axillary body temperature $\leq 37.2^{\circ} \mathrm{C}$ and absence or very mild degree of symptoms.

Patients in the IFC group showed an attenuated and shortened course of illness: at day 4 a percentage of $76.8 \%$ in the IFC group was free of fever vs $56.7 \%$ in the ST group and $17.0 \%$ had absence or very mild symptoms vs $7.5 \%$ of ST group.

Considering the entire study period of 14 days, data highlighted a more prompt occurrence of "treatment response" in the IFC group (Figure 6).

As a consequence to the significantly better response to treatment, patients in the IFC group showed a shorter time to symptom alleviation (1-2 days), a faster resumption of normal activities (IFC $48 \%$ vs ST 28\%) (Figure 7) and a significantly lower median disease severity. Simultaneously, significantly less standard symptomatic medication was needed in the IFC group (Figure 8). Safety results confirmed the good tolerability of IFC. 
According to authors' conclusions, IFC as an add-on therapy improved response, shortened the duration of URTIs, and lowered symptoms severity. The results suggest that IFC enhanced the self-recovery of the patients, and partly replaced the need for conventional symptomatic treatment.

\section{TONSILLITIS AND PHARYNGITIS}

\section{Definition}

Tonsillopharyngitis is an infection of the palatine tonsils and pharynx that can be either acute or recurrent. Acute pharyngitis is caused by Group A beta-hemolytic streptococcus (GABHS) in the $15-30 \%$ of cases in children, and in 5 to 20 percent in adults [58]; the remaining cases are considered viral [59]. Tonsillopharyngitis is a common reason for pediatric health care visits: in the USA, approximately $10 \%$ of children seen by medical care providers each year have pharyngitis, and $25-50 \%$ of these children have GABHS pharyngitis [60]. Among school-aged children, the incidences of acute sore throat, swab-positive GABHS, and serologically confirmed GABHS infection are 33,13 , and 8 per 100 children/years, respectively [58].

The signs and symptoms of acute tonsillitis can be similar to other infectious causes (e.g. painful swallowing, sore throat, cervical lymphadenopathy), while recurrent tonsillitis is characterized by more specific symptoms (e.g. enlarged tonsils, caseous detritus or liquid pus in the cryps, ridged thickening and chronic hyperemia of the edges of the palatine arches).

Diagnosis is based on clinical findings. To positively identify whether the etiology is bacterial or viral, a rapid strept test (RST) or a throat swab culture can be performed.

If tonsillopharyngitis is not properly treated, serious complications, as rheumatic fever and related cardiovascular disorders or poststreptococcal glomerulonephritis, can occur.

\section{Treatment}

The goals of treatment are to: attenuate the severity of symptoms, shorten the course of disease, reduce the number of disease-related absences in school or at work, help prevent serious complications, and improve the quality of life [61]. The treatment of tonsillitis, both in acute and in recurrent form, is based on pharmacological measures, as symptom- atic medications, antipyretics and analgesics, and on other measures, as gargling, throat compresses, and ultrasound. Only GABHS infections diagnosed by RST or culture should be treated with antibiotics [62]. According to a recent US study [63], antibiotics were prescribed during $60 \%$ of pharyngitis visits for children, while bacteria are responsible for pharyngitis only in $37 \%$ of cases: the inappropriate antibiotic treatment, suggested by this study, is becoming a major issue, in relation to development of resistances and hypersensitivity. To date, the management of bacterial pharyngitis remains controversial, and there is a lack of uniformity between different guidelines [64].

Tonsillectomy is indicated for repeated GABHS tonsillitis and severe acute tonsillitis persistent despite antibiotics. According to a recent Cochrane review, the results of surgery are controversial: the effects are modest, and they should be balanced with the risks related to the surgical procedure [65].

As for the other URTIs, natural remedies and homeopathy are used for tonsillitis and pharyngitis: according to data from a recent international survey, conducted on 138 pediatricians, general practitioners and ear-nose-throat specialists in 7 countries, homeopathic remedies were prescribed as a supportive therapy by $62 \%$ of participants in case of acute tonsillopharyngitis, and by $59 \%$ of participants in case of recurrent tonsillopharyngitis [55].

\section{Tonsilotren ${ }^{\circledR}$ (use and dosage)}

Tonsilotren ${ }^{\circledR}$ (Deutsche Homöopathie Union, DHU, Karlsruhe, Germany) is a homeopathic complex composed of a combination of 5 single remedies: Atropinum sulfuricum D5, Hepar sulfuris D3, Kalium bichromicum D4, Mercurius bijodatus D8, and Silicea D2 [66]. In acute tonsillitis, the suggested dosage for children < 1 year is 1 tablet $(250 \mathrm{mg}) 3$ times a day; for children 1-11 years, the initial dose is 1 tablet every 2 hours (maximum 8 times a day) and the subsequent dose is 1 tablet 3 times a day. In recurrent tonsillitis, the dosage for children $<12$ years is 1 tablet 3 times a day: the treatment should continue for 6-8 weeks in 3-4 treatment cycles per year. Tonsilotren ${ }^{\circledR}$ can be used on its own or in combination with prescribed medication. An interval of approximately 30 minutes should be kept between the intake of Tonsilotren ${ }^{\circledR}$ and eating or drinking [66]. 


\section{From literature}

Tonsilotren ${ }^{\circledR}$ has been studied in a series of clinical studies, since the early nineties [23,24,67-73]. Here we present the main results of the two most recent studies in the pediatric setting, one in patients with acute tonsillitis [23] and one in patients with recurrent tonsillitis [24].

Friese et al. [23] performed a multicenter, randomized, placebo-controlled, double-blind study on 158 patients aged 6-10 years affected by acute tonsillitis and without indication for an antibiotic treatment. The study group received Tonsilotren ${ }^{\circledR}$ at dosage of 1 tablet for hour (max. 12 times a day) until onset of improvement, afterwards the dosage was $1 \mathrm{tab}-$ let 3 times a day; the control group received placebo. The primary outcome criterion was the decrease of total sum score of tonsillitis typical symptoms from baseline to day 4; the 5 tonsillitis typical symptoms included difficulties swallowing, pain in throat, salivation, reddening and fever, rated on a 4-point-scale. Secondary outcome criteria were: the remission of tonsillitis typical single symptoms assessed on day 4, the time until onset of treatment effect, the outcome of treatment , and the safety and tolerability of Tonsilotren ${ }^{\circledR}$. The overall observational period was 6 days.

The decrease of total sum score of tonsillitis typical symptoms from baseline to day 4 was significantly higher in the study group (- 7.2 vs -2.7$)$, as well as the remission of tonsillitis typical single symptoms assessed on day 4 (Figure 9).

Moreover, $92.4 \%$ of patients showed a full recovery or at least a moderate improve- ment after 6 days of treatment, compared to the $43.1 \%$ in the control group. The complete recovery rate was $75.9 \%$ in the study group vs $16.5 \%$ in the control group, and the deterioration rate was $3.8 \%$ in the study group vs $22.8 \%$ in the control group. Tonsilotren ${ }^{\circledR}$ showed an excellent safety and tolerability: no adverse event was related to the treatment and almost $100 \%$ of patients and physicians rated the tolerability as "very good" or "good".

The most recent study on Tonsilotren ${ }^{\circledR}$ were performed by Palm and colleagues between January 2013 and April 2015, and the results were presented at the $13^{\text {th }}$ Congress of the European Society of Pediatric Otorhinolaryngology (ESPO) [24]. A randomized, controlled, clinical trial was conducted in Germany, Spain and Ukraine on 256 patients aged $6-60$ years $(86 \leq 12$ years, 51 between $12-18$ years, $119 \geq 18$ years) with moderate recurrent tonsillitis (RT). Conventional symptomatic drugs were allowed to be prescribed to all the patients involved, while the test group received additionally Tonsilotren ${ }^{\circledR}$ for 3 treatment periods of 8 weeks, each treatment period being followed by a 8 to 12 weeks period without Tonsilotren ${ }^{\circledR}$. The estimated rate of diagnosed acute throat infections per year was the primary outcome measure; other outcome measures were the severity of RT symptoms and the antibiotics consumption due to acute throat infections. The primary outcome was significantly lower in the test group compared to the control group (0.59; 95\%-CI: $0.41-0.85$ vs. 1.35; 95\%-CI: 1.09-1.66; $\mathrm{p}=0.0002$; Poisson regression model) [24]. The RT symptoms
Figure 9. Remission of tonsillitis typical single symptoms assessed on day 4. Adapted by [23]

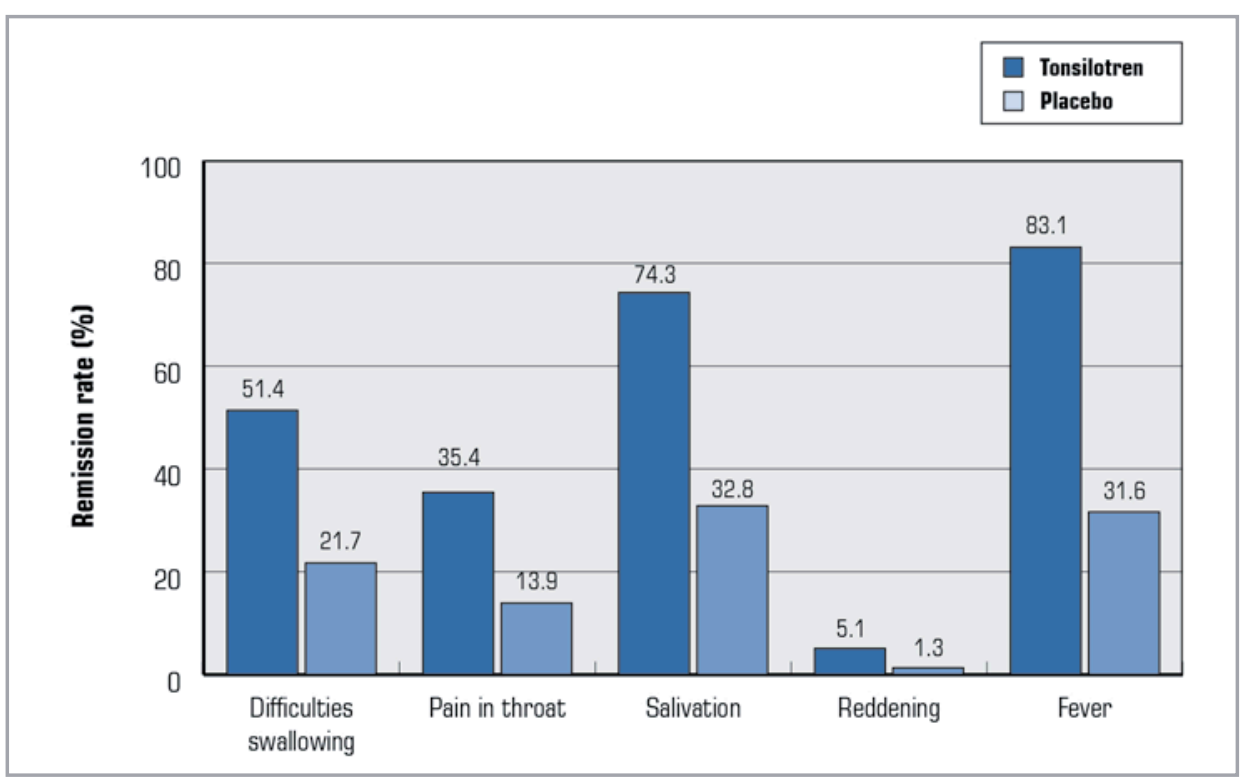


occurred in a significantly lower percentage of patients in the test group compared to the control group: difficulties in swallowing / sore throat were seen in $25 \%$ of test group vs. $52.5 \%$ of control group ( $\mathrm{p}<0.0001$; Chi2 test), halitosis in $30.5 \%$ vs. $67.5 \%$ ( $\mathrm{p}<0.0001$; Chi2 test) and caseous purulent plugs in the tonsillar crypts in $45.3 \%$ vs. $66.7 \%$ $(p=0.0007$; Chi2 test) [24]. Significantly lower was also the antibiotics consumption due to acute throat infections: $37 \%$ in the test group vs. 58.2 in the control group (95\%CI: 9.13-33.36; $\mathrm{p}=0.0008$; Chi2 test) [24]. Positive results were also registered about the safety of Tonsilotren ${ }^{\circledR}$ : in the test group 225 adverse events were reported, three of these were related to Tonsilotren ${ }^{\circledR}[24]$.

\section{CONCLUSION}

In recent years the use of herbal remedies and homeopathic products in children is highly increasing, as outlined by analysis carried out in the USA and in Europe [36]. Very often parents ask the pediatricians to give children these kind of remedies, especially in the early childhood years or for the treatment of mild ailments, such as those related to teething or infantile colic. The biggest concern for parents comes generally from the risk of adverse events due to conventional drugs; furthermore, for some disorders, there is no standard of care in mainstream medicine. In these cases the use of homeopathic products confer the advantage of having an excellent profile of safety and tolerability together with efficacy, as demonstrated by recent studies presented and discussed in this article [20-24].

Homeopathy can also be useful as adjunctive therapy for conventional drugs: recent studies show that, even in children, very often homeopathic products are used together with conventional therapies. In these cases the use of homeopathic medicines demonstrated to alleviate symptoms, contributing to shorten the duration of the disease and decreasing the use of symptomatic drugs, as here reported by the study on Influcid ${ }^{\circledR}$ [22]. In some pathologies, in particular, such as recurrent respiratory infections in children, the use of symptomatic drugs is very high, although not particularly effective. A recent Cochrane review confirmed the controversial results on non-prescription, overthe-counter (OTC) medicines for acute cough due to URTIs: in the absence of good evidence for or against the effectiveness of OTC medicines in acute cough, the Authors stressed the importance of prescribing these drugs with caution, to avoid the risk of adverse events [74].

There is a strong interest of pediatricians towards herbal products and homeopathic: many studies have reported a growing demand for validated information, also to better address the demands and needs of patients and their parents [7]. In recent years it has also increased the number of pediatricians and physicians who choose to treat themselves with natural and homeopathic remedies.

Although homeopathy is still debated, there are some studies that attest to the efficacy and safety in children. In this article we present and discuss five studies that have shown the effectiveness of homeopathic products for the treatment of infantile colic, teething, URTIs and tonsillopharyngitis [20-24]. As authors active in clinical practice we hope that such issues will be investigated with further trials and updated reviews on existing literature.

\section{REFERENCES}

1. National Institutes of Health. Complementary and Alternative Medicine. Collection Development Manual. https://www.nlm.nih.gov/tsd/acquisitions/cdm/subjects24.html (last accessed June 2016)

2. Ventola CL. Current issues regarding complementary and alternative Medicine (CAM) in the United States: Part 1: the widespread use of CAM and the need for better-informed health care professionals to provide patient counseling. PT 2010; 35: 461-8

3. Zuzak TJ, Boňková J, Careddu D, et al. Use of complementary and alternative medicine by children in Europe: published data and expert perspectives. Complement Ther Med 2013;21 Suppl 1:S34-47. doi: 10.1016/j.ctim.2012.01.001

4. Kemper KJ, Vohra S, Walls R; Task Force on Complementary and Alternative Medicine; Provisional Section on Complementary, Holistic, and Integrative Medicine. American Academy 
of Pediatrics. The Use of Complementary and Alternative Medicine in Pediatrics. Pediatrics 2008; 122:1374-86

5. Ekins-Daukes S, Helms PJ, Taylor MW, et al. Paediatric homoeopathy in general practice: where, when and why? Br J Clin Pharmacol 2005; 59: 743-9

6. Beer AM, Balgradean M, Burlaka I, et al. Usage and attitudes towards natural remedies and homeopathy in general paediatrics: A cross-country overview. Global Pediatric Health 2016; 3: 1-9. doi: 10.1177/2333794X15625409

7. Kemper KJ. Pediatricians' Recommendations for CAM therapies. Ambulatory Pediatrics 2004; 4: $482-7$

8. Brinkhaus $\mathrm{B}$, Witt $\mathrm{CM}$, Jena $\mathrm{S}$, et al. Integration of complementary and alternative medicine into medical schools in Austria, Germany and Switzerland-results of a cross-sectional study. Wien Med Wochenschr 2011; 161: 32-43. doi: 10.1007/s10354-010-0834-x

9. Heusser P. We need a conceptual integration of conventional and complementary medicine. Forsch Komplementmed 2010; 17: 217

10. Haidvogl M, Riley DS, Heger M, et al. Homeopathic and conventional treatment for acute respiratory and ear complaints: a comparative study on outcome in the primary care setting. BMC Complement Altern Med 2007; 7: 7

11. Taylor JA, Jacobs J. Homeopathic ear drops as an adjunct to standard therapy in children with acute otitis media. Homeopathy 2011; 100: 109-15. doi: 10.1016/j.homp.2011.03.002

12. Sinha MN, Siddiqui VA, Nayak C, et al. Randomized controlled pilot study to compare Homeopathy and Conventional therapy in Acute Otitis Media. Homeopathy 2012; 101: 5-12. doi: 10.1016/j.homp.2011.08.003

13. Pham B, Klassen TP, Lawson ML, et al. Language of publication restrictions in systematic reviews gave different results depending on whether the intervention was conventional or complementary. J Clin Epidemiol 2005; 58: 769-76

14. Bell IR, Schwartz GE. Enhancement of adaptive biological effects by nanotechnology preparation methods in homeopathic medicines. Homeopathy 2015; 104: 123-38

15. Rutten L, Mathie RT, Fisher P, et al. Plausibility and evidence: the case of homeopathy. M Med Health Care Philos 2013; 6: 525-32

16. Kleijnen J, Knipschild P, ter Riet G. Trials of homeopathy. BMJ 1991; 302: 960

17. Linde K, Clausius N, Ramirez G, et al. Are the clinical effects of homeopathy placebo effects? A meta-analysis of placebo-controlled trials. Lancet 1997; 350: 834-43

18. Cucherat M, Haugh MC, Gooch M, et al. Evidence of clinical efficacy of homeopathy. A metaanalysis of clinical trials. HMRAG. Homeopathic Medicines Research Advisory Group. J Clin Pharmacol 2000; 56: 27-33

19. Shang A,Huwiler-Muntener K, Nartey L, et al. Are the clinical effects of homoeopathy placebo effects? Comparative study of placebo-controlled trials of homoeopathy and allopathy. Lancet 2005; 366: 726

20. Ilyenko LI, Kholodova IN, Syr'eva TN, et al. [Treatment of functional gastrointestinal disturbances in infants in the early year of life]. Pediatrija 2010; 89: 118-122

21. Jong MC, Verwer S, Vijver L, et al. A randomized open comparative clinical trial on the effectiveness, safety and tolerability of a homeopathic medicinal product for the treatment of painful teething in children. Altern Integr Med 2015; 4: 178. doi: 10.4172/2327-5162.1000178

22. Thinesse-Mallwitz M, Maydannik V, KellerT, et al. A Homeopathic Combination Preparation in the Treatment of Feverish Upper Respiratory Tract Infections: An International Randomized Controlled Trial. Forsch Komplementmed 2015; 22: 163-70. doi: 10.1159/000430762.

23. Friese KH, Timen GE, Zabalotnyi DI. [Homeopathy in children with nonstreptococcal tonsillitis. Study proves efficacy and tolerability of a homeopathic combination medicine.] Der Kassenarzt 2006; 6: 402

24. Palm J, Kishchuck VV, Keller T, et al. Results of an international, randomized, controlled clinical trial with a complex homeopathic medication in chronic tonsillitis. Poster presentation, $13^{\text {th }}$ Congress of the European Society of Pediatric Otorhinolaryngology (ESPO), Lisbon, 18-21 June 2016

25. Wessel MA, Cobb JC, Jackson EB, Harris GS, Detwiller AC. Paroxysmal fussing in infancy, sometimes called colic. Pediatrics 1954; 14: 421-34

26. Lucassen PL, Assendelft WJ. Systematic review of treatments for infant colic. Pediatrics 2001; 108: $1047-8$

27. Stifter CA, Bono MA. The effect of infant colic on maternal self-perceptions; perceptions and mother - infant attachment. Child Care Health Dev 1998; 24: 339-51 
28. Humphry RA, Hock E. Infants with colic: A study of maternal stress and anxiety. Infant Ment Health J 1989; 10: 263-72. doi: 10.1002/1097-0355(198924)10:4<263::AIDIMHJ2280100404>3.0.CO;2-4

29. Rogovik AL, Goldman RD. Treating infants' colic. Can Fam Physician 2005; 51: 1209-11

30. Danielsson B, Hwang CP.Treatment of infantile colic with surface active substance (simethicone). Acta Paediatr Scand 1985; 74: 446-50

31. MetcalfTJ, Irons TG, Sher LD, et al. Simethicone in the treatment of infant colic: a randomized, placebo-controlled, multicenter trial. Pediatrics 1994; 94: 29-34

32. Hwang CP, Danielsson B. Dicyclomine hydrochloride in infantile colic. Br Med J (Clin Res Ed) 1985; 291: 1014

33. Weissbluth M, Christoffel KK, Davis AT. Treatment of infantile colic with dicyclomine hydrochloride. J. Pediatr 1984; 104: 951-5

34. Savino F, Brondello C, Cresi F, et al. Cimetropium bromide in the treatment of crisis in infantile colic. J Pediatr Gastroenterol Nutr 2002; 34: 417-19

35. Hall B, Chesters J, Robinson A. Infantile colic: a systematic review of medical and conventional therapies. J Paediatr Child Health 2012; 48: 128-37. doi: 10.1111/j.1440-1754.2011.02061.x

36. Dicyclomine Hydrochloride. Rx Drugs Info. Dicyclomine Hydrochloride (dicyclomine hydrochlodide), 2015. Available on http://rxdrugsinfo.com/drug-info-label/dicyclominehydrochloride (last accessed June 2016)

37. Savino F, Cordisco L, Tarasco V, et al. Lactobacillus reuteri DSM 17938 in infantile colic: a randomized, double-blind, placebo-controlled trial. Pediatrics 2010; 126: e526-33

38. Sung V,Hiscock H, Tang ML, et al. Treating infant colic with the probiotic Lactobacillus reuteri: double blind, placebo controlled randomised trial. BMJ 2014;1: g2107. doi: 10.1136/bmj.g2107

39. Savino F, Ceratto S, De Marco A, et al. Looking for new treatments of Infantile Colic. Ital J Pediatr 2014; 40: 53. doi: 10.1186/1824-7288-40-53

40. Savino F, Cresi F, Castagno E, et al. A randomized double blind placebo-controlled trial of a standardized extract of Matricariae recutita, Foeniculum vulgare and Melissa officialis (ColiMil) in the treatment of breast-fed colicky infants. Phytother Res 2005; 19: 335-40

41. Alexandrovich I, Rakovitskaya O, Kolmo E, et al. The effect of fennel (Foeniculum vulgare) seed oil emulsion in infantile colic: a randomized, placebo-controlled study. Altern Ther Health Med 2003; 9: 58-61

42. Thompson EA, Bishop JL, Northstone K. The use of homeopathic products in childhood: data generated over 8.5 years from the Avon Longitudinal Study of Parents and Children (ALSPAC). J Altern Complement Med 2010; 16: 69-79. doi: 10.1089/acm.2009.0007

43. Summary of product characteristics. Cinababy, oral drops, solution (QRD 9.1).v.04. October 2014

44. McIntyre GT, McIntyre GM. Teething troubles? Br Dent J 2002; 192: 251-5

45. Sood S, Sood M. Teething: myths and facts. J Clin Pediatr Dent 2010; 35: 9-13

46. FDA Drug Safety Communication: FDA recommends not using lidocaine to treat teething pain and requires new Boxed Warning, 2014. Available on http://www.fda.gov/Drugs/DrugSafety/ ucm402240.htm (last accessed June 2016)

47. FDA Drug Safety Communication: Reports of a rare, but serious and potentially fatal adverse effect with the use of over-the-counter (OTC) benzocaine gels and liquids applied to the gums or mouth, 2011. Available on http://www.fda.gov/drugs/drugsafety/ucm250024.htm (last accessed June 2016)

48. Summary of product characteristics. Chamodent (QRD 9.1).v.05. September 2015

49. Heikkinen T, Järvinen A. The common cold. Lancet 2003; 361: 51-9

50. Eckel N, Sarganas G, Wolf IK, et al. Pharmacoepidemiology of common colds and upper respiratory tract infections in children and adolescents in Germany. BMC Pharmacol Toxicol 2014; 15: 44. doi: 10.1186/2050-6511-15-44

51. Moro ML, Marchi M, Gagliotti C, et al. Progetto Bambini e Antibiotici [ProBA] Regional Group. Why do paediatricians prescribe antibiotics? Results of an Italian regional project. BMC Pediatr 2009; 9: 69

52. NICE guidelines CG69. Respiratory tract infections (self-limiting): prescribing antibiotics. 2014. Available on http://www.nice.org.uk/guidance/cg69 (last accessed June 2016)

53. Bücheler R, Meisner C, Kalchthaler B, et al. "Off-label” [Verschreibung von Arzneimitteln in der ambulanten Versorgung von Kindern und Jugendlichen]. Dtsch Med Wochenschr 2002; 127: $2551-7$

54. Friedman BC, Schwabe-Warf D, Goldman R. Reducing inappropriate antibiotic use among children with influenza infection. Canadian Family Physician 2011; 57: 42-4 
55. Salatino S, Gray A. Integrative management of pediatric tonsillopharyngitis: an international survey. Complimentary therapies in Clinical Practice 2016; 22: 29-32. doi: 10.1016/j. ctcp. 2015.11.003

56. Summary of product characteristics. Nisylen, tablets (QRD 9.1). v.06, April 2016

57. Heger M. International outcome study NI001: upper respiratory infections and feverish colds - effectiveness and safety of Nisylen tablets; biometrical report. DHU, Karlsruhe, 1997

58. Choby BA. Diagnosis and treatment of streptococcal pharyngitis. Am Fam Physician 2009; 79: $383-90$

59. Cohen JF, Cohen R, Levy C, et al. Selective testing strategies for diagnosing group A streptococcal infection in children with pharyngitis: a systematic review and prospective multicentre external validation study. CMAJ 2015; 187: 23-32. doi: 10.1503/cmaj.140772

60. Simon HK. Pediatric Pharyngitis. Medscape, 2016. Available online on http://emedicine. medscape.com/article/967384-overview\#a5 (last accessed June 2016)

61. Windfuhr JP, Toepfner N, Steffen G, et al. Clinical practice guideline: tonsillitis I. Diagnostics and nonsurgical management. Eur Arch Otorhinolaryngol 2016; 273: 973-87. doi: 10.1007/ s00405-015-3872-6

62. Cohen R. Defining the optimum treatment regimen for azithromycin in acute tonsillopharyngitis. Pediatr Infect Dis J 2004; 23(2 Suppl): S129-34

63. Dooling KL, Shapiro DJ, Van Beneden C, et al. Overprescribing and inappropriate antibiotic selection for children with pharyngitis in the United States, 1997-2010. JAMA Pediatr 2014; 168: 1073-4. doi: 10.1001/jamapediatrics.2014.1582.

64. Van Brusselen D, Vlieghe E, Schelstraete P, et al. Streptococcal pharyngitis in children: to treat or not to treat? Eur J Pediatr 2014; 173: 1275-83. doi: 10.1007/s00431-014-2395-2

65. Burton MJ, Glasziou PP, Chong LY, et al. Tonsillectomy or adenotonsillectomy versus nonsurgical treatment for chronic/recurrent acute tonsillitis. Cochrane Database Syst Rev 2014; 11: CD001802. doi: 10.1002/14651858.CD001802.pub3

66. Summary of product characteristics. Tonsilotren H, tablets (QRD 9.1). v.06. September 2014

67. Becker S, Kunstmann KD. [Acute tonsillitis - successful treatment with a homeopathic complex medicine.] Ärztezeitschrift für Naturheilverfahren 1995; 36 (5): 372-377

68. Friese KH. [Tonsilotren H bei akuter Angina tonsillaris.] Der Kassenarzt 1997; 40: 36-43

69. Moshchich P, Borzenko I, Schmidt G. [Influence of Tonsilotren on clinical findings and course of tonsillitis with children]. Pediatriya, Akusherstvo ta Ginekologiya 1997; 1: 37-8

70. Moshchich P, Borzenko I, Moshchich A. [Tonsilotren, complex homeopathic drug for treatment of acute tonsillitis with children.] Ukrainskom Homyeopaticheskom Yezhegodnike 1998; 1: 173-4

71. Bokovoy A, Heger M, Shutzle B. [Medical treatment of children having catarrhal tonsillitis.] Liky Ukrainy 1999; 2: 53-6

72. Baranow AA, Moshchich PS, Friese KH, Heger M. [Alternative treatment for acute tonsillitis. Results of an open multinational observation study following the outcomes research approach.] Der Kassenarzt 2000; 11: 40-9

73. Niederle S. [Acute non-streptococcal tonsillitis in children. A double-blind, placebo-controlled study verifies efficacy and tolerability of homeopathic therapy.] Der Kassenarzt 2001; 21: 33-4

74. Smith SM, Schroeder K, Fahey T. Over-the-counter (OTC) medications for acute cough in children and adults in community settings. Cochrane Database Syst Rev 2014; 11: CD001831 